\title{
Positive Deep-UV Resist Based on Silylated Polyhydroxystyrene
}

\author{
Makoto Murata, Eiichi Kobayashi, Mikio Yamachika, \\ Yasutaka Kobayashi, Yoshiji Yumoto, Takao Miura \\ Development Center \\ Japan Synthetic Rubber Co., Ltd. \\ 100 Kawajiricho, Yokkaichi, Mie 510 Japan
}

\begin{abstract}
A chemically amplified, positive-working resist system based on silylated polyhydroxystyrene has shown its potential ability for application to the quarter micron lithography. The present paper describes the recent improvement on resist performance achieved through studies on effects of polymer characteristics and process conditions. Especially reported is the methods for avoiding the T-shaped pattern profile which is often observed for many chemically amplified, positiveworking resist systems.

Although the development is still on the way, the silylated polyhydroxystyrene resist shows excellent properties on resolution capability, sensitivity and process latitude.
\end{abstract}

\section{INTRODUCTION}

We have been extensively investigating a chemically amplified, positive-working resist system which is based on silylated polyhydroxystyrene (SiPHS) aiming at KrF excimer laser lithography $1-3$ ). The resist is composed of the polymer and photoacid generator (PAG). SiPHS is an advantageous material to achieve high resolution because it is highly transparent at $248 \mathrm{~nm}$. Another advantage is chemical amplification (CA) for high sensitivity 4-6). Figure 1 shows the CA scheme of the system. Upon exposure PAG releases acid, and catalytic cleavage of the protective silyl group proceeds by action of the generated acid. This catalytic amplification mechanism contributes to raise the resist sensitivity beyond the limitation of quantum yield.

We have reported on the optimization of the protecting silyl group and the degree of silylation 3). Trimethylsilyl group shows good performance because of its desirable high hydrolysis rate and adequate stability in the absence of acid. The degree of silylation defined as the silylation ratio which is the number of the protected hydroxyl groups against all the hydroxyl groups of the polymer has been optimized from the viewpoints of thermal stability and solubility.

The present paper describes the further optimization of polymer characteristics and process conditions mainly focused on the methods to prevent surface skin formation. Several recent papers 


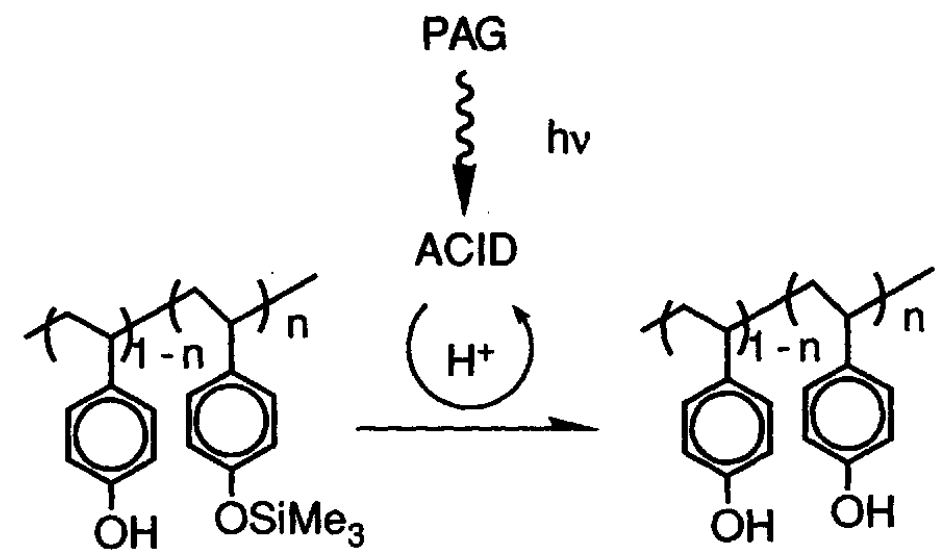

Figure 1 CA scheme of the SiPHS based resist system.

point out a curious phenomenon of CA type positive resists; i.e., formation of the surface skin which is insoluble in developer and causes T-shaped pattern profile or, if worse, tunnel-like development ${ }^{7-8}$ ). We have found that the skin formation is strongly dependent on the polymer characteristics and the process conditions, and thus by controlling these factors we can obtain a skin-free resist.

\section{EXPERIMENTAL}

\section{Apparatus}

The followings are the apparatuses for SiPHS characterization and resist evaluation. A Toso HLC-8020 was employed to measure polystyrene-equivalent molecular weight of polymer, and silylation ratio was calculated from its ${ }^{1} \mathrm{H}-\mathrm{NMR}$ spectrum recorded on a JEOL EX90A by comparing the peak areas of trimethylsilyl protons and aromatic ones. IR spectra were recorded on a JASCO FT/IR-8000. Dissolution rates of polymers and resists were measured using a Perkin-Elmer Development Rate Monitor (DRM). Lithographic imaging was performed on KrF Excimer Laser Steppers, Canon FPA-3000EX1 (NA=0.45) or Nikon NSR 1755EX8A.

\section{RESULTS AND DISCUSSION}

\section{Molecular weight (Mw) of the polymer}

Dissolution behavior of the polymer material is a significant factor to determine resist performance. It is generally important to maximize the difference in dissolution rate between the exposed and the unexposed regions. From this point of view, in our system, polyhydroxystyrene which is produced after desilylation reaction is favorable to have higher

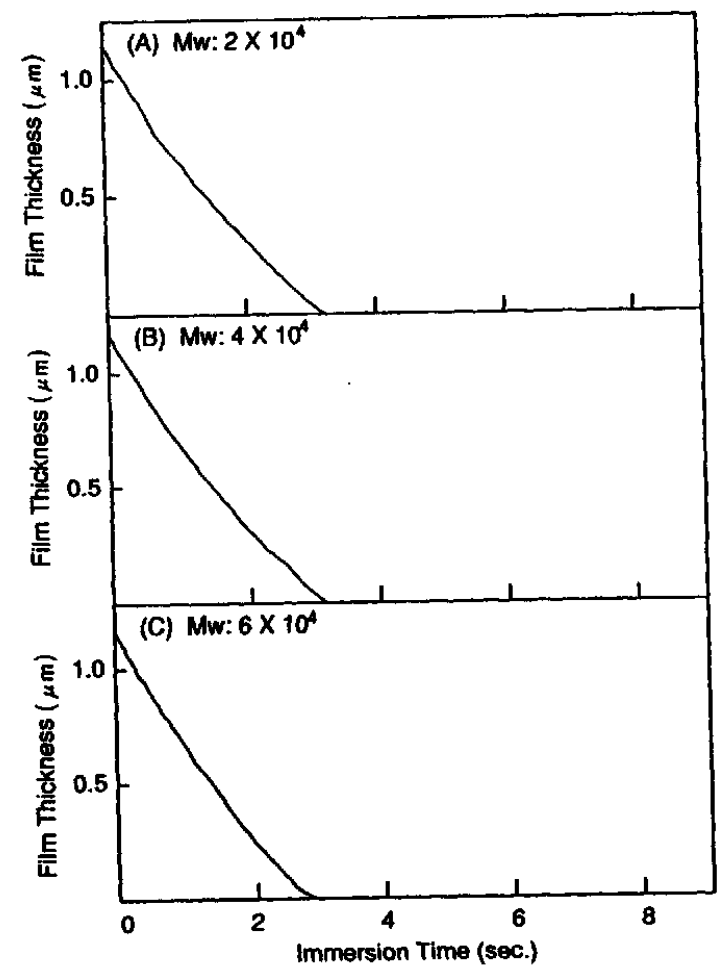

Figure 2

Dissolution behavior of polyhydroxystyrene films in an aqueous solution of tetramethylammonium hydroxide (2.38 wt\%). 
dissolution rate. We have synthesized polyhydroxystyrene polymers varying in $\mathrm{Mw}$ from about 20000 to 60000 and measured their dissolution rates as shown in Figure 2. The rate has been found to be almost independent of $\mathrm{Mw}$ within this $\mathrm{Mw}$ range as a similar result was reported by Long et al9).

Although further investigation was carried out on Mw influence to lithographic imaging, no significant difference was observed due to the difference in $\mathrm{Mw}$.

\section{Silylation ratio of the polymer}

As we previously reported, it is necessary to decide the silylation ratio in the balance of solubility and thermal durability 3 ). Besides, DRM measurement of SiPHS resists varying in silylation ratio has revealed that silylation ratio affects dissolution behavior of the exposed resist. As shown in Figure 3, an induction period was observed at the initial stage of development and it becomes longer as the silylation ratio increases. This induction shows decrease in solubility at the resist surface so that it seems to have relation to the surface skin formation. This issue is discussed later in the present paper.

\section{Post-exposure bake (PEB) temperature}

Baking temperature, especially PEB temperature, has been reported critical to many $\mathrm{CA}$ systems, and most of the reports point out that resist sensitivity varies by changing PEB conditions 10 ). In order to examine the influence of PEB temperature on performance of SiPHS resist, we measured dissolution rates of the resist films and also carried out lithographic imaging with varying $\mathrm{PEB}$ temperature.

The stepwise dissolution curves were observed without PEB due to the standing wave effect as shown in Figure 4, while after PEB at $90^{\circ} \mathrm{C}$ for 2 minutes they became smooth. This indicates that diffusion of the generated acid during PEB alleviates its lamella-like distribution in the exposed region. Another interesting phenomenon is again induction period which appears only after PEB as is discussed later.

In the lithographic evaluation, an even more interesting result was obtained. Unlike other CA type resist systems, sensitivity of SiPHS resist did not depend much upon PEB temperature as shown in Figure 5, which would be an advantageous point for its practical use in device fabrication. Figure 6 shows IR spectral changes of a resist film measured in 15 minutes after

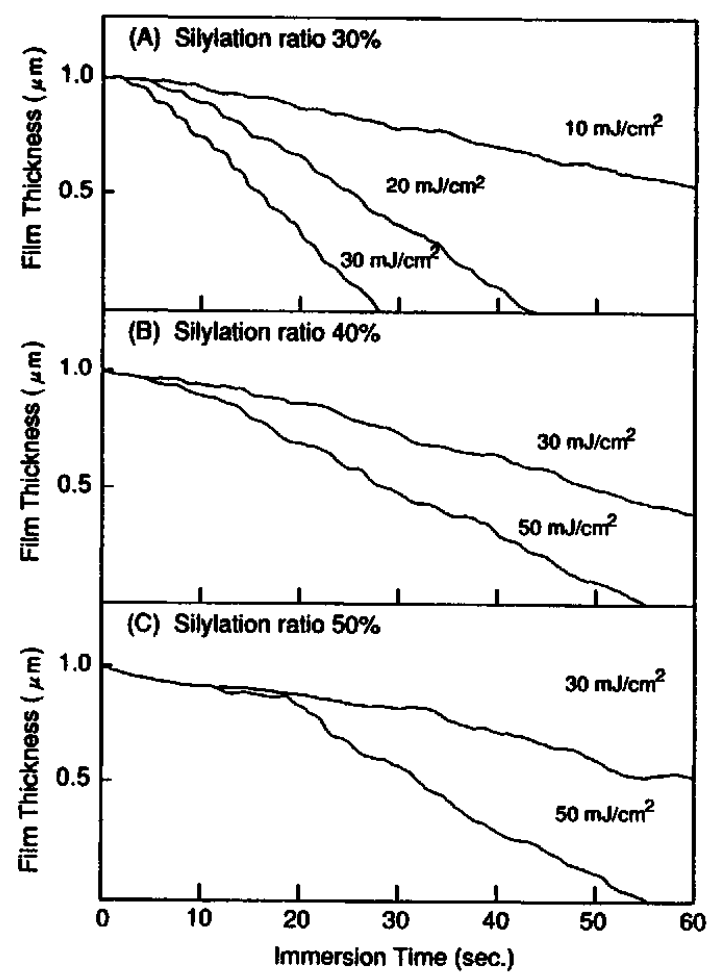

Figure 3

Dissolution behavior of exposed resist films in an aqueous solution of tetramethylammonium hydroxide (2.38 wt\%).

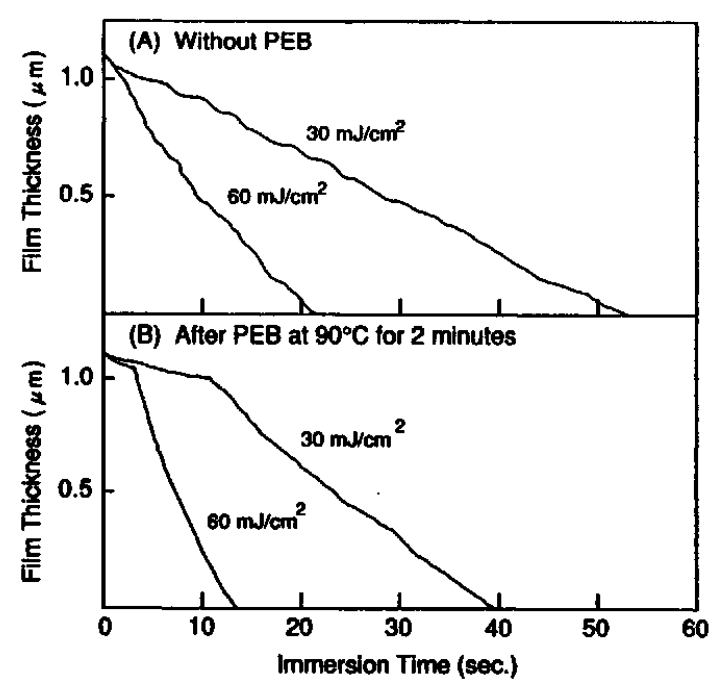

Figure 4

Dissolution behavior of exposed resist films in an aqueous solution of tetramethylammonium hydroxide ( $2.38 w t \%)$. 


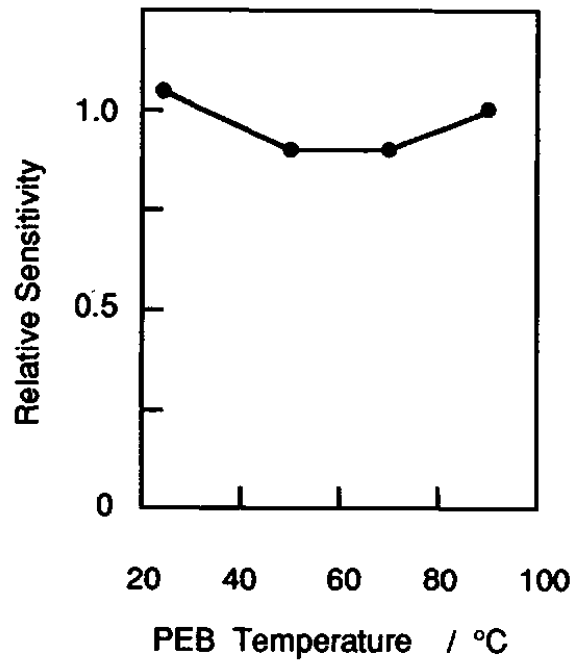

Figure 5

Dependence of the optimum sensitivity for 0.4 um line patterning on PEB temperature normalized at $90^{\circ} \mathrm{C}$.

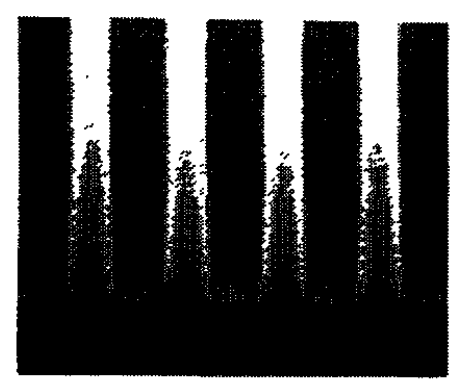

(a) $0.26 \mu \mathrm{m}$ line and space pairs.

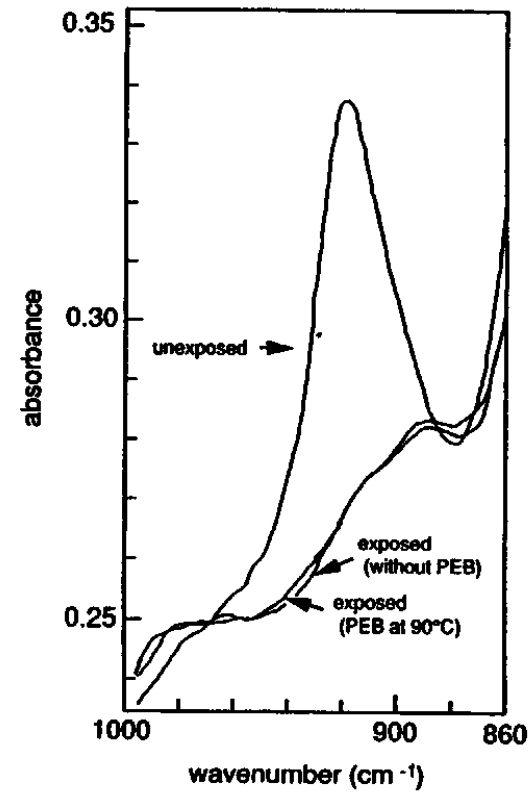

Figure 6 Desilylation of resist film.

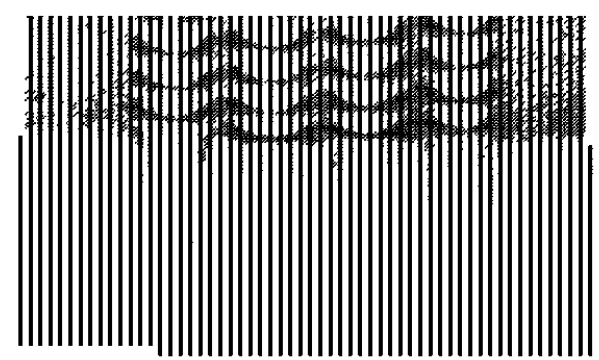

(b) $0.28 \mu \mathrm{m}$ holes.

Figure 7 Resolution capability of SiPHS based resist.

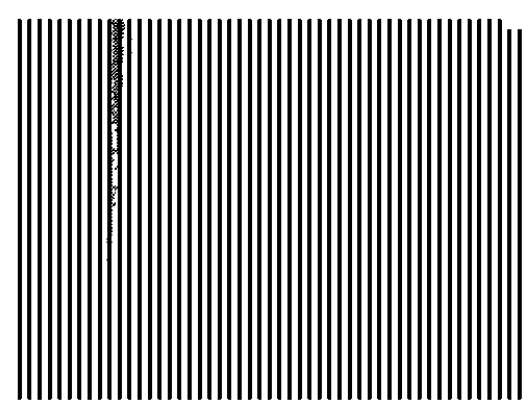

(a) As developed.

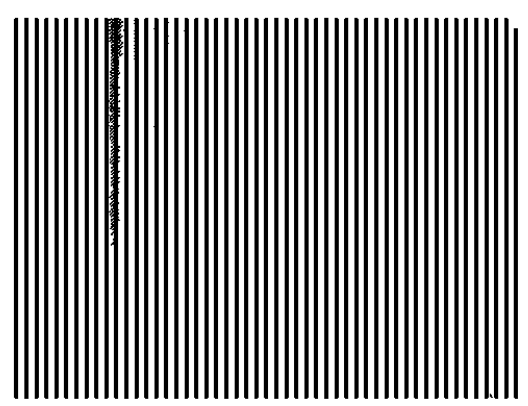

(b) After bake at $150^{\circ} \mathrm{C}$ for 2 minutes.

Figure 8 Thermal durability of SiPHS based resist. 
exposure with and without PEB. The two exposed spectra are nearly identical, indicating complete cleavage of silyl ether group during this time period. This quick decomposition of the protecting group without PEB should contribute to the PEB temperature independence of resist sensitivity.

\section{Prevention of surface skin formation}

Although the mechanisms of surface skin formation have not been clarified yet, proposed are neutralization of the acid by environmental contamination, absence of PAG or generated acid in the resist surface due to volatilization or migration towards inside the film, and so forth 7,8 ).

Considering the above described results of DRM measurement, the migration mechanism seems applicable to the SiPHS system. Hult et al have reported that spin coating of resist depletes PAG concentration at the resist surface when the PAG has poor solubility in the polymer 11 ). This depletion effect can increase for the resist with highly silylated polymer because solubility of PAG is likely to decrease against the silylation ratio. Besides, silicone's low surface energy may accelerate the depletion as the silicon-rich segments of the polymer can be dominant at the surface possibly resulting in exclusion of PAG. At higher PEB temperatures, solvent in a resist film volatilizes at the surface to raise $\mathrm{Tg}$ of the polymer so that the reaction chain length may be reduced. Thus, the unreacted silyl ether groups are thought to cause the surface skin.

Although we ought to continue our study to elucidate the mechanisms, the DRM study suggests a solution to the problem. In order to prevent the surface skin formation, it is recommended to adjust polymer characteristics and process conditions; i.e., low silylation ratio and low PEB temperature can relieve the problem.

\section{Evaluation of the resist}

As a result of the further investigation to achieve the optimized conditions in both resist materials and processes, SiPHS resist shows good lithographic characteristics. Figure 7 shows an imaging result of a SiPHS based resist. $0.26 \mu \mathrm{m}$ line and space pairs along with $0.28 \mu \mathrm{m}$ contact holes are formed in a $1.0 \mu \mathrm{m}$ thick resist film on a silicon substrate with mask linearity down to $0.30 \mu \mathrm{m}$ line and space pairs. This resist shows a $1.0 \mu \mathrm{m}$ range of the depth of focus for $0.30 \mu \mathrm{m}$ line and space pairs. When PEB is applied 4 hours after exposure, slight thinning in line width is observed comparing with the ones without the delay, while the skin formation is still unobserved.

Figure 8 shows thermal durability of the resist. A $30 \mu \mathrm{m}$ square patten does not deform at all after a bake at $150^{\circ} \mathrm{C}$ for 2 minutes.

\section{SUMMARY}

A positive deep-UV resist consisting of silylated polyhydroxystyrene and photoacid generator was further investigated. DRM measurement detected formation of insoluble surface layer when the resist employs a highly silylated polymer and is treated with a high temperature PEB, and lowering silylation ratio or PEB temperature is found to be effective to prevent its formation. The resist is capable of imaging $0.26 \mu \mathrm{m}$ line and space pairs along with $0.28 \mu \mathrm{m}$ contact holes in good pattern profiles.

\section{ACKNOWLEDGEMENTS}

The authors would like to thank both Canon and Nikon companies for their kind offers of stepper demonstrations with the SiPHS resist. The authors also would like to thank Japan Synthetic Rubber for supporting the present study.

\section{REFERENCES}

1) T. Yamaoka, N. Nishiki, K. Koseki, M. Koshiba, Polym. Eng. Sci. , 29, 856 (1989) 
2) M. Murata, T. Takahashi, M. Koshiba, S. Kawamura, T. Yamaoka, Proc. SPIE, 1262, 8 (1990)

3) M. Murata, E. Kobayashi, Y. Yumoto, T. Miura, T. Yamaoka, J. Photopolym. Sci. Technol. , 4, No. 3, 509 (1991)

4) H. Ito and C. G. Willson, ACS Symp. Ser. , 242, 11 (1984)

5) W. E. Feely, J. C. Imhof, C. M. Stein, T. A. Fischer, M. W. Legenza, Polymer Eng. Sci. , 26, $1101(1986)$

6) T. Ueno, H. Shiraishi, N. Hayashi, K. Tadano, E. Fukuma, T. Iwayanagi, Proc. SPIE, 1262, $26(1990)$

7)G. Schwartzkopf, N. N. Niazy, S. Das, G. Surendran, J. B. Covington, Proc. SPIE, 1466, 26 (1991)

8) S. A. MacDonald, N. J. Clecak, H. R. Wendt, C. G. Willson, C. D. Snyder, C. J. Knors, N. B. Deyoe, J. G. Maltabes, J. R. Morrow, A. E. McGuire, S. J. Holmes, Proc. SPIE, 1466, 2 (1991)

9) T. Long, F. Rodriguez, Proc. SPIE, 1466, 188 (1991)

10) C. G. Willson, ACS Symp Ser., 219 ch. 3(1983)

11)A. Hult, S. A. MacDonald, C. G. Willson, Macromolecules, 18, 1804(1985) 